\title{
Interplay between Syntax and Semantics during Sentence Comprehension: ERP Effects of Combining Syntactic and Semantic Violations
}

\author{
Peter Hagoort
}

\begin{abstract}
This study investigated the effects of combined semantic and syntactic violations in relation to the effects of single semantic and single syntactic violations on language-related event-related brain potential (ERP) effects (N400 and P600/ SPS). Syntactic violations consisted of a mismatch in grammatical gender or number features of the definite article and the noun in sentence-internal or sentence-final noun phrases (NPs). Semantic violations consisted of semantically implausible adjective-noun combinations in the same NPs. Combined syntactic and semantic violations were a summation of these two respective violation types. ERPs were recorded while subjects read the sentences with the different types of violations and the correct control sentences. ERP effects were computed relative to ERPs elicited by the sentence-internal or sentence-final nouns. The size of the N400 effect to the semantic violation was increased by an additional syntactic
\end{abstract}

\section{INTRODUCTION}

Recent accounts of the human language system (Jackendoff, 1999, 2002; Levelt, 1999) assume a tripartite architecture, which consists of separate processing levels for conceptual/semantic information, orthographic/ phonological information, and syntactic information. Based on this architecture, most current models of language processing agree that in on-line sentence processing, different types of constraints are very quickly taken into consideration during speaking and listening/ reading. Constraints on how words can be structurally combined operate next to qualitatively distinct constraints on the combination of word meanings, on the grouping of words into phonological phrases, and on their referential binding into a discourse model. Together, these constraints solve the "binding problem" for language, or, in other words, how speakers and writers, listeners and readers bind single-word information into multi-word utterances and complex messages (Hagoort, Brown, \& Osterhout, 1999). violation (the syntactic boost). In contrast, the size of the P600/ SPS to the syntactic violation was not affected by an additional semantic violation. This suggests that in the absence of syntactic ambiguity, the assignment of syntactic structure is independent of semantic context. However, semantic integration is influenced by syntactic processing. In the sentence-final position, additional global processing consequences were obtained as a result of earlier violations in the sentence. The resulting increase in the N400 amplitude to sentence-final words was independent of the nature of the violation. A speeded anomaly detection task revealed that it takes substantially longer to detect semantic than syntactic anomalies. These results are discussed in relation to the latency and processing characteristics of the N400 and P600/SPS effects. Overall, the results reveal an asymmetry in the interplay between syntax and semantics during on-line sentence comprehension.

Despite fairly wide agreement on the types of constraints that are effective during the formulation and the interpretation of sentences, exactly how these are implemented in the overall sentence processing machinery is still a matter of considerable debate in psycholinguistics. One of the key issues is if, when, and how the assignment of a syntactic structure to an incoming string of words and the semantic integration of single word meanings interact during reading/listening. One view is that in sentence comprehension, the syntactic analysis is autonomous and initially not influenced by semantic variables (Frazier, 1987). Semantic integration can be influenced by syntactic analysis, but it does not contribute to the computation of syntactic structure. Some recent empirical evidence for this view is provided in a study of O'Seaghdha (1997), measuring naming latencies. An alternative view maintains that semantic information can guide or contribute to the syntactic analysis of the utterance. This view is mainly supported by studies showing that the reading of syntactically ambiguous sentences is immediately influenced by lexical or more global semantic information (e.g., Trueswell, Tanenhaus, \& Garnsey, 1994; Trueswell, Tanenhaus, \& Kello, 1993; Altmann \& Steedman, 1988; Tyler \& Marslen-Wilson, 1977). 
Some of the discrepancies between the different views on this topic are due to the fact that no clear distinction is made between cases where the syntactic constraints are, at least temporarily, indeterminate with respect to the structural assignment (syntactic ambiguity), and cases where these constraints are sufficient to determine the syntactic analysis. In the former case, there is evidence for an immediate influence of nonsyntactic context information on the structure that is assigned (Tanenhaus \& Trueswell, 1995). However, for the latter case, although it has not been studied as intensely, the available evidence seems to provide support for a certain level of syntactic autonomy (O'Seaghdha, 1997).

The purpose of the present study is to shed light on the interplay between syntactic and semantic information, when the syntactic structure can be fully computed from the lexical-syntactic (i.e., lemma) information that is retrieved on the basis of the incoming string of words (see Vosse \& Kempen, 2000 for a computational model). The approach taken here was to exploit the fact that different types of electrophysiological brain activity (i.e., event-related brain potentials [ERPs]) have been shown to honor the distinction between the processing of syntactic and semantic information (cf. Hagoort et al., 1999).

ERPs are electrical changes generated by the brain but usually recorded from electrodes placed on the scalp. The changes are induced by an external stimulus or an internal processing event. In principle, qualitatively different processing events can show up as latency or amplitude modulations of qualitatively distinct ERP components. An important example in this context is the distinction between semantic and syntactic ERP effects in comprehension. The processing of semantic information is found to influence the amplitude of a negative-going ERP component between roughly 250 and $550 \mathrm{msec}$, and with a maximal amplitude at about $400 \mathrm{msec}$ (Kutas \& Hillyard, 1980). This amplitude modulation is referred to as the N400 effect. Usually, the N400 effect is larger over posterior electrode sites than over frontal sites. The N400 effect can be observed to words in the context of another word, of a sentence, or of a larger discourse (van Berkum, Hagoort, \& Brown, 1999). The easier the match between the lexical-semantics of a particular content word and the semantic specification of the context, the more reduced the amplitude of the N400. The antecedent conditions of the N400 effect suggest that it is especially sensitive to semantic integration processes (Chwilla, Brown, \& Hagoort, 1995; Brown \& Hagoort, 1993, 1999).

In addition to the semantic N400 effect, two syntaxrelated ERP effects have been reported in recent years. One is a negative shift in the ERP waveform within the same latency range as the $\mathrm{N} 400$, but with a clearly more frontal distribution. The frontal negative shift goes under different names, but it is most often referred to as the Left Anterior Negativity (LAN), although in many, cases the distribution is bilateral (Hagoort, Wassenaar, \& Brown, 2003). The second syntax-related ERP is a positive-polarity shift that starts at about $500 \mathrm{msec}$ and can continue for another $500 \mathrm{msec}$. This is referred to here as the P600/SPS effect. The frontal negativities are observed to morphosyntactic violations (Münte \& Heinze, 1994; Münte, Heinze, \& Mangun, 1993) and to violations of word category (Friederici, Hahne, \& Mecklinger, 1996). The latter violations refer to a mismatch between the word category of a particular word (e.g., noun) and the word category that the phrase structure requires at this specific position in the unfolding sentence. The P600/SPS effect is seen to a larger series of syntactic violations, including phrase structure violations, subcategorization violations, and violations in the agreement of number and case (cf. Hagoort et al., 1999 for a review), but also to violations of syntactic preferences in syntactically ambiguous sentence structures (van Berkum et al., 1999; Osterhout, Holcomb, \& Swinney, 1994). For the purpose of this study, it is important to note that a P600/SPS is also found following a violation of agreement in grammatical gender in Dutch (Hagoort \& Brown, 1999; van Berkum, Brown, \& Hagoort, 1999), a result that indicates that the processing of grammatical gender information is not a semantic-content-driven but a syntactic-form-driven process (Hagoort \& Brown, 1999).

To study the interplay between semantic integration and syntactic assignment in comprehension, a full factorial design was used, in which subjects were not only confronted with semantic and syntactic violations but also with the combination of these violation types. Figure 1 depicts the logic behind the current study. On the basis of the observed ERP effects to semantic and syntactic violations, the inference can be made that semantic integration processes feed into the generators of the N400, whereas syntactic assignment processes feed into the generators of the P600/SPS (and possibly other ERPs, such as the LAN). Most likely, each of these components is generated by a distributed ensemble of neural generators (Osterhout \& Nicol, 1999). Under the reasonable assumption that the generators of the $\mathrm{N} 400$ and P600/SPS are nonoverlapping, Helmholtz superposition principle holds. According to this principle, the effects of nonoverlapping generators summate in the scalp-recorded ERPs. However, this will only occur if also the processes that drive the activity of these nonoverlapping generators are fully independent. Such would be the case if semantic integration and syntactic assignment are totally independent processes. If, however, these processes interact, nonadditivity will result.

Note that this logic does not assume that the N400 and the P600/SPS are language specific. As has been argued by Osterhout and Hagoort (1999), there is no firm evidence that the neural generators responsible for the language-relevant ERP effects are language specific. But crucially, although the existence of language-related 
ERP effects does not allow the inference that they are language specific, it is the case that within the domain of language processing, different ERP effects are triggered by operations at different levels of human language processing (for a more extensive discussion, see Hagoort et al., 1999). Thus, the finding of qualitatively distinct ERP effects for semantic and syntactic processing operations supports the claim that these two levels of language processing are domain specific. However, domain specificity should not be confused with modularity (Fodor, 1993), which makes the much stronger claim that domain-specific levels of processing operate autonomously without interaction (informational encapsulation). Although domain specificity is widely assumed in models of language processing, there is much less agreement about the organization of the cross-talk between different levels of sentence processing (cf. Boland \& Cutler, 1996). This study will provide data relevant to this latter issue.

So far, only a few ERP studies have tested the interaction of syntactic and semantic processing by combining syntactic and semantic violations in a fully factorial design (Friederici, Steinhauer, \& Frisch, 1999; Osterhout \& Nicol, 1999; Ainsworth-Darnell, Shulman, \& Boland, 1998; Gunter, Stowe, \& Mulder, 1997). Although, on the whole, these studies suggest nonadditivity of semantic and syntactic violation effects, for reasons to be discussed below, the nature of the nonadditivity was not clear. Therefore, conclusions about the precise nature of the interaction between semantic integration and syntactic assignment are difficult to draw from these studies. Osterhout and Nicol (1999) report a slightly smaller N400 effect and a smaller P600/SPS to the combined semantic and syntactic violation in comparison to the summation of the single semantic and syntactic violation effects. Friederici et al. (1999) reported an N400 effect for the semantic violation, but they did not find an N400 effect for the combined semantic and syntactic violation. Ainsworth-Darnell et al. (1998) found an N400 effect to semantic anomalies, a P600/SPS to syntactic violations, and both an N400 effect and a P600/SPS to the combined violation. In one experiment, Gunter et al. (1997) reported an approximate summation for the combined violation of the single syntactic and semantic violations. In a second experiment, however, the authors found the P600/SPS to the double violation to be reduced relative to the single syntactic violation.

With respect to determining the nature of the interaction between semantic and syntactic processing, these studies suffer from two potential problems. One problem is that, in three of the studies, the ERPs that were compared were elicited by different words in the relevant conditions (Ainsworth-Darnell et al., 1998; Osterhout \& Nicol, 1999; Gunter et al., 1997). This might have introduced subtle deviations from linearity, for instance, as a result of interactions with certain lexical characteristics of the critical words (CWs; Osterhout \& Nicol, 1999). In two of the studies (Friederici et al., 1999; Gunter et al., 1997), the CWs were in sentence-final position. It is found in a number of ERP studies that processing problems somewhere in the sentence tend to elicit not only a local ERP effect to the lexical element that embodies the processing problem but also a more global effect to sentence endings (Hagoort, Brown, \& Groothusen, 1993; Osterhout \& Holcomb, 1992, 1993; Osterhout \& Nicol, 1999). These sentence-ending effects are most likely due to sentence "wrap-up," response, and/or decision processes. Consequently, CWs in sentence-final positions show an overlap of local and global processing effects. This again complicates an analysis of possible nonlinearities such that clear conclusions about the directionality of potential interactions between semantic integration and syntactic assignment are difficult to draw.
Figure 1. The logic of the experiment: Syntactic processes trigger the generators of the P600/SPS, semantic processes trigger the generators of the N400. Nonadditivity of scalprecorded waveforms resulting from semantic and syntactic processing are indicative of cross-talk between these two types of processing operations.

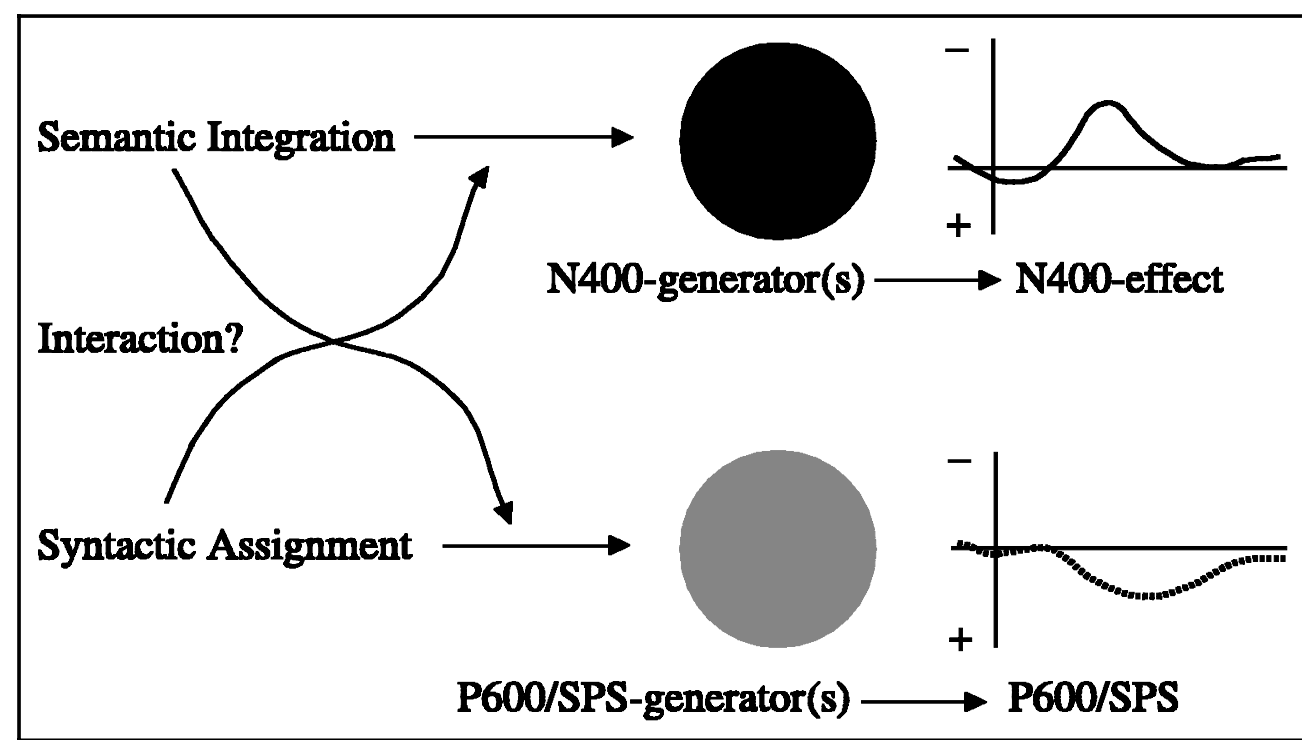


In the present study, these potential confounding factors were remedied by having the identical CWs in all conditions and by presenting the CWs in nonfinal sentence position. However, in a separate set of conditions, CWs were presented in sentence-final position to allow for a direct comparison between sentence-internal and sentence-final word position effects.

The syntactic violation conditions in this study exploited the characteristics of the grammatical gender system in Dutch. Dutch nouns have either one of two grammatical genders: common gender and neuter gender (van Berkum, 1996). When produced with a definite article, a singular noun phrase (NP) is gender marked by the article of the noun. The definite article "de" is used for nouns of common gender, whereas the definite article "het" is used for nouns of neuter gender. In addition to the violation of grammatical gender in singular NPs, a violation of number agreement was realized for plural NPs. In Dutch, the article "de" has to be used for definite plural NPs, the article "het" can only be used in combination with a singular NP. When used in combination with a plural NP, it violates the number agreement constraints.

The semantic violation was realized by semantically unacceptable combinations of an adjective and its following noun (e.g., honest umbrella), in which, for instance, the adjective requires an animate noun, but is followed by an inanimate one.

ERPs were recorded while participants read sentences containing NPs with either a correct agreement between the definite article and the noun, or sentences in which there was a gender/number mismatch between article and noun, for instance, when a neuter article is combined with a noun of common gender (see Table 1 for an example of the stimulus materials). In addition, the NPs could be semantically acceptable or anomalous. Finally, the combined violation condition contained sentences in which the syntactic and semantic violations were superimposed. After reading each sentence in a word by word presentation format, subjects indicated by a button press whether the sentence was acceptable or not. In a follow-up study, subjects had to give a

Table 1. Example Sentences of the Materials, with Sentence-Internal (1) and Sentence-Final Violations (2)

The critical nouns are italicized, incorrect articles and anomalous adjectives are in bold. Synt -: syntactic violation; Sem -: semantic violation; Synt -, Sem - : combined syntactic and semantic violation. The example sentences are in Dutch, with the literal English translation in brackets. In the English translations, the following abbreviations are used: com $=$ article/noun of common gender; neut $=$ neuter gender article. Examples (1a) and (1b) are for the singular nouns, and (2a) and (2b) are for the plural nouns. For Dutch plural nouns, the article "de" is the only option.

(1a) De kapotte paraplu staat in de garage.

Het kapotte paraplu staat in de garage.

(Synt -)

De eerlijke paraplu staat in de garage.

(Sem -)

Het eerlijke paraplu staat in de garage.

(Synt -, Sem -)

(The $\mathrm{com}_{\mathrm{com}} /$ The $_{\text {neut }}$ broken/honest umbrella $_{\mathrm{com}}$ is in the garage.)

(1b) De bekwame vaklieden zien de kwaliteit van het produkt.

Het bekwame vaklieden zien de kwaliteit van het produkt.

(Synt -)

De zoute vaklieden zien de kwaliteit van het produkt.

$($ Sem -)

Het zoute vaklieden zien de kwaliteit van het produkt.

(Synt -, Sem -)

(The $_{\text {plural/com }} /$ The $_{\text {singular/neut }}$ skilled/salty craftsmen $_{\text {plural }}$ appreciate the quality of the product.)

(2a) Cindy sliep slecht vanwege de griezelige droom.

Cindy sliep slecht vanwege het griezelige droom.

(Synt -)

Cindy sliep slecht vanwege de verkouden droom.

(Sem -)

Cindy sliep slecht vanwege het verkouden droom.

(Synt -, Sem -)

(Cindy slept badly due to the $\mathbf{e}_{\mathrm{com}} / \mathbf{t h e}_{\text {neut }}$ scary/sniffing dream $_{\mathrm{com}}$.)

(2b) De uitzending is verstoord door de rumoerige jongeren.

De uitzending is verstoord door het rumoerige jongeren.

(Synt -)

De uitzending is verstoord door de bewolkte jongeren.

(Sem -)

De uitzending is verstoord door het bewolkte jongeren.

(Synt -, Sem -)

(The broadcasting is interfered with by the $\mathrm{plural}_{\text {/com }} / \mathbf{t h e}_{\text {singular/neut }}$ noisy/cloudy youngsters $_{\text {plural }}$.) 
speeded response to the same sentences, whenever they detected an anomaly.

\section{RESULTS}

\section{Acceptability Judgments}

According to the acceptability judgements that were given after each sentence, subjects found $95 \%$ of the correct sentences acceptable. For the sentences containing a violation, the results were as follows: For the sentences with a syntactic violation, 97\% was rated as unacceptable, for the sentences with a semantic violation, $90 \%$ was unacceptable, and the combined violation was rated as unacceptable in $99 \%$ of the cases. This clearly demonstrates the sensitivity of subjects to both syntactic and semantic violations.

\section{ERP Data}

According to the logic of the experiment, if semantic integration and syntactic assignment are both fully autonomous processes, the ERP effect of the double violation should be a summation of the ERP effects of the syntactic and semantic violations. The inspection of the subtraction waveforms (not presented here), however, indicated that the double violation could not be modeled as a summation of the single semantic and syntactic violations. The observed nonadditivity suggests an interaction between semantic integration and syntactic assignment at some stage of language comprehension. To determine the exact nature of this processing interaction, sentence-internal and sentence-final ERP effects were analyzed in more detail. The results of these analyses are presented below.

\section{Sentence-Internal Effects}

For the sentence-internal NPs, Figure $2 \mathrm{~A}$ and B shows overlays of the ERP waveforms at a central midline electrode site $(\mathrm{Cz})$ for the noun in the three violation conditions and the control condition. Different ERP components are clearly visible in the ERP waveform for all conditions (see Figure 2A). A N1 component at around $120 \mathrm{msec}$ is followed by a P2 component at about 200 msec. These ERP components are followed by the N400 with a maximal amplitude at roughly $400 \mathrm{msec}$. The N1 amplitude shows some differences across conditions. Especially the semantic violation results in a slightly reduced N1. However, because the P2 amplitudes are very similar for all conditions, the N400 amplitude seems unaffected by the $\mathrm{N} 1$ differences. Moreover, at other electrode sites (i.e., LTP, Pz, RTP, OL, OR; see Figure 3) the N1 amplitude for the semantic violation is not different, or even slightly larger than the N1 amplitude of the other conditions. Especially the N400 amplitude difference between the semantic violation and the combined violation, therefore, cannot be explained away as a consequence of differences at the level of the N1 amplitude (see Figure 3).

The amplitude of the N400 is largest for the combined violation. Relative to the control condition, the N400 amplitude is also increased for the semantic violation, but to a lesser extent than for the combined violation. Inspection of the other electrode sites (Figure 3) show that the N400 effect of the combined violation is largest over all electrode sites. The syntactic violation shows an increased amplitude in the 300-500 msec latency range over left anterior-temporal sites.

The N400 is followed by a positive deflection that is largest for the syntactic violation. This positive deflection starts at about $500 \mathrm{msec}$ and carries over into the processing epoch of the following word. Inspection of the other electrode sites (see Figure 3 ) shows that this positive shift is largest over centro-parietal sites, with an equal distribution over both hemispheres. On the basis of the polarity, the latency, and the scalp distribution of this ERP effect, it can be unambiguously characterized as a P600/SPS.

\section{Sentence-Final Effects}

Figure $4 \mathrm{~A}$ and $\mathrm{B}$ shows overlays of the waveforms for the sentence-final NPs. As for the sentence-internal waveforms, a clear N400 effect is visible that is largest for the combined violation. Figure 5 shows that the amplitude increase of the combined violation relative to the semantic violation is most prominent over anterior sites, but absent over posterior sites. The N400 is followed by a P600/SPS, with a similar distribution across the scalp as for the sentence-internal violation. However, in contrast to the sentence-internal syntactic violation, the P600/SPS to the syntactic violation in sentence-final position is preceded by a widely distributed negative shift within the 300-500 msec latency range. Over the lateral sites, this negative shift increases from frontal to parietal sites (see Figure 5). Over the midline sites, the effect is largest over the central electrode site $(\mathrm{Cz})$.

As can be seen in Figure 5, the P600/SPS was most marked over posterior sites including $\mathrm{Cz}$. No hemispheric asymmetries in the size of the P600/SPS were observed.

\section{Statistical Analyses}

ERPs were quantified by mean amplitude measures in 300-500 and 500-700 msec time windows following the onset of the $\mathrm{CW}$, which is the noun in the sentenceinitial or sentence-final NP. The first window covers the N400, the second window the P600/SPS. For the N400 window, mean amplitudes were computed relative to a 150 msec baseline preceding the CW. For the P600/SPS, mean amplitudes were computed relative to a baseline of 300-500 msec following the onset of the $\mathrm{CW}$ to 
Figure 2. ERP waveforms at the central midline electrode $(\mathrm{Cz})$ for the correct condition and the three types of violations at a sentence-internal position. The critical noun is presented at Time 0 . At 600 msec, the next word appeared on the screen. Negativity is plotted upwards in this and all other figures. (A) This part of the figure shows the effects in the N400 window. The boost of the N400 effect in the combined semantic and syntactic violation is marked

in blue. (B) This part of the figure shows the effects in the P600/SPS window after renormalization in the 300-500 msec latency range.

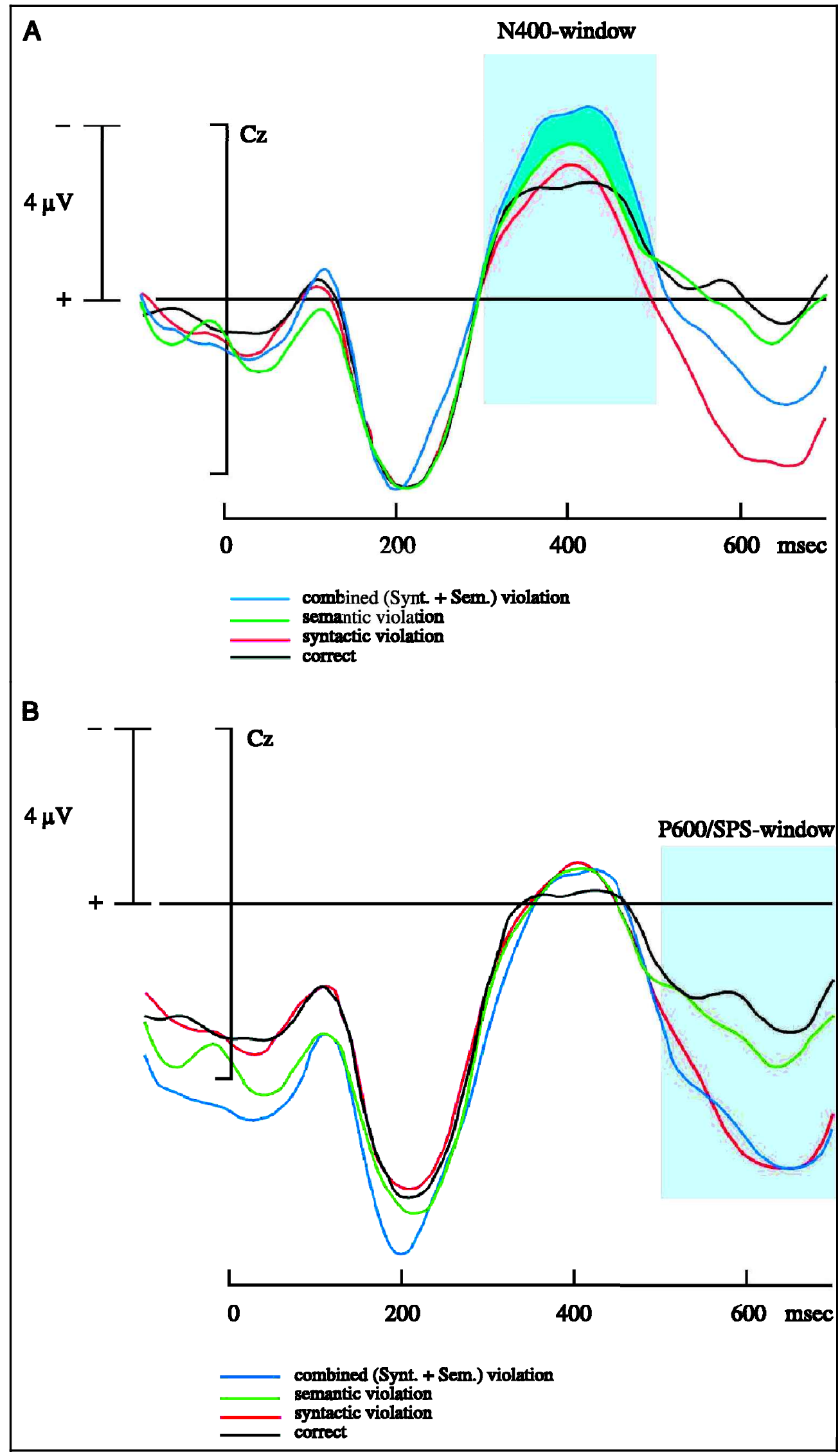


Figure 3. ERP waveforms at all 13 electrode sites for the four conditions in sentence-internal position. The critical noun is presented at Time 0 . At $600 \mathrm{msec}$, the next word appeared on the screen.
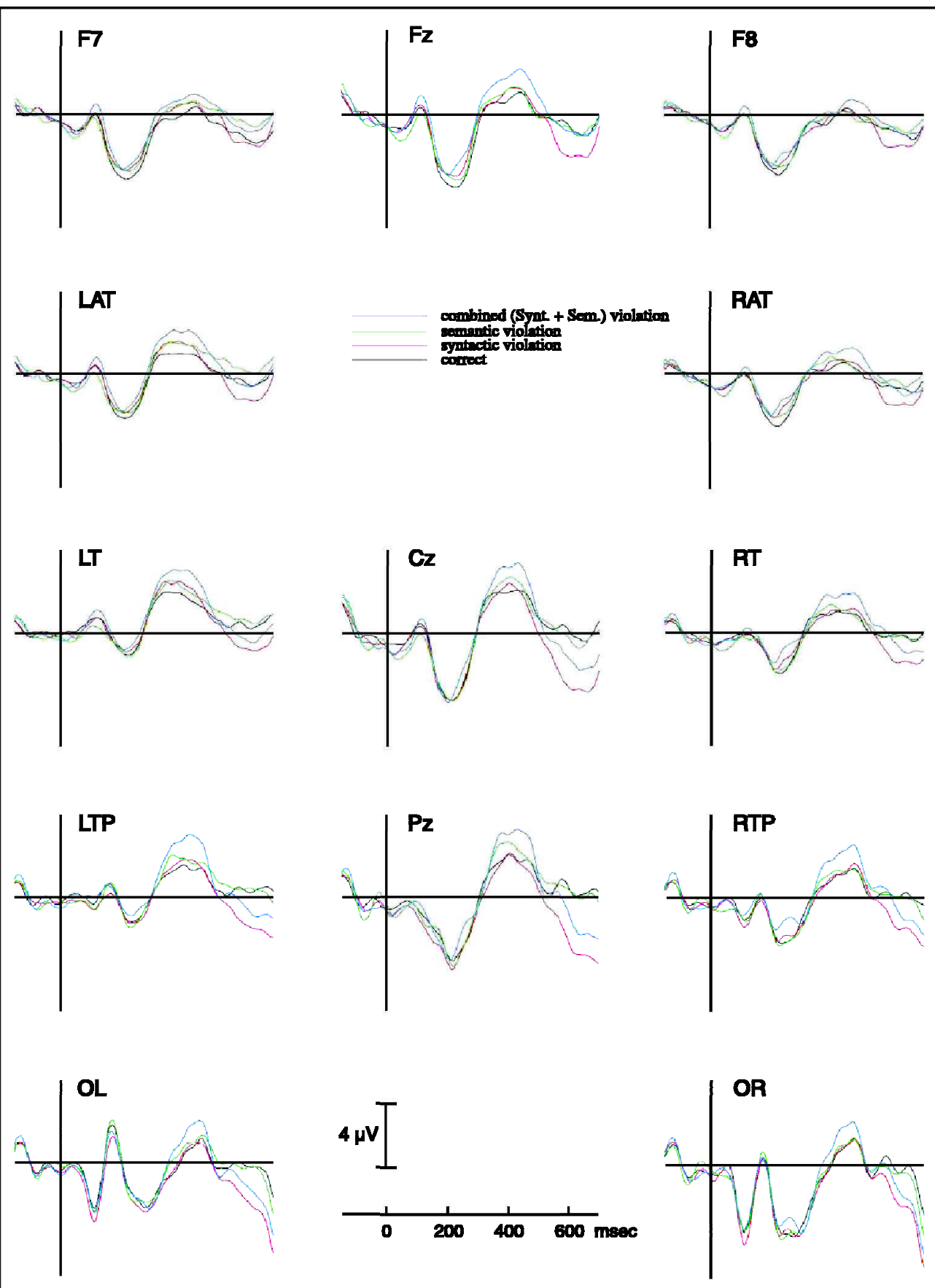

compensate for the preceding N400 amplitude differences (see below). Given the limited number of trials (20) in the conditions separated for noun number (singular, plural), data were collapsed over number. The resulting mean amplitude values were entered into an omnibus ANOVA, with grammaticality (2 levels: violation, correct), semantics (2 levels: violation, correct), position (2 levels: sentence-internal, sentence-final) and electrode site (13 levels) as within-subjects factors. The omnibus ANOVA was followed by three planned comparisons, one for each type of violation. For the repeatedmeasures analyses of variance, the Greenhouse-Geisser correction (Winer, 1971) was applied for effects with more than one degree of freedom in the numerator. The corrected degrees of freedom and $p$ values are reported. When appropriate, reliable main effects in the presence of a significant interaction were followed by tests of the simple effects. Because main effects of position and electrode are not informative with respect to the relevant issues of this study, these effects will not be reported.

\section{N400}

The omnibus ANOVA on the mean amplitude in the 300-500 msec latency range resulted in significant main 
Figure 4. ERP waveforms at the central midline electrode $(\mathrm{Cz})$ for the correct condition and the three types of violations at the sentence-final position. The critical noun is presented at Time 0. (A) This part of the figure shows the effects in the N400 window. The boost of the N400 effect in the combined semantic and syntactic violation is marked in blue. (B) This part of the figure shows the effects in the P600/SPS window after renormalization in the 300-500 msec latency range.

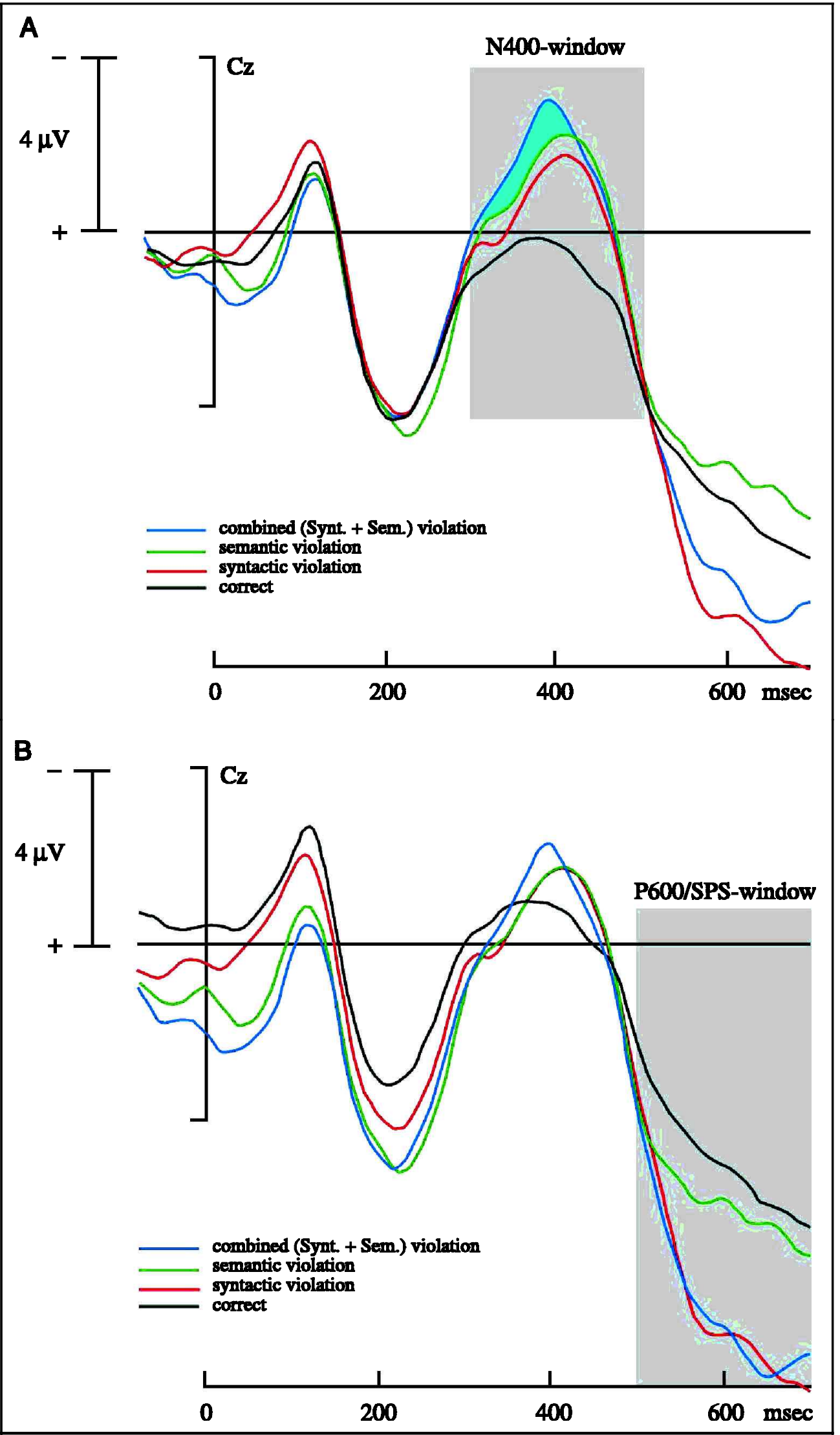


Figure 5. ERP waveforms at all 13 electrode sites for the four conditions in sentence-final position. The critical noun is presented at Time 0
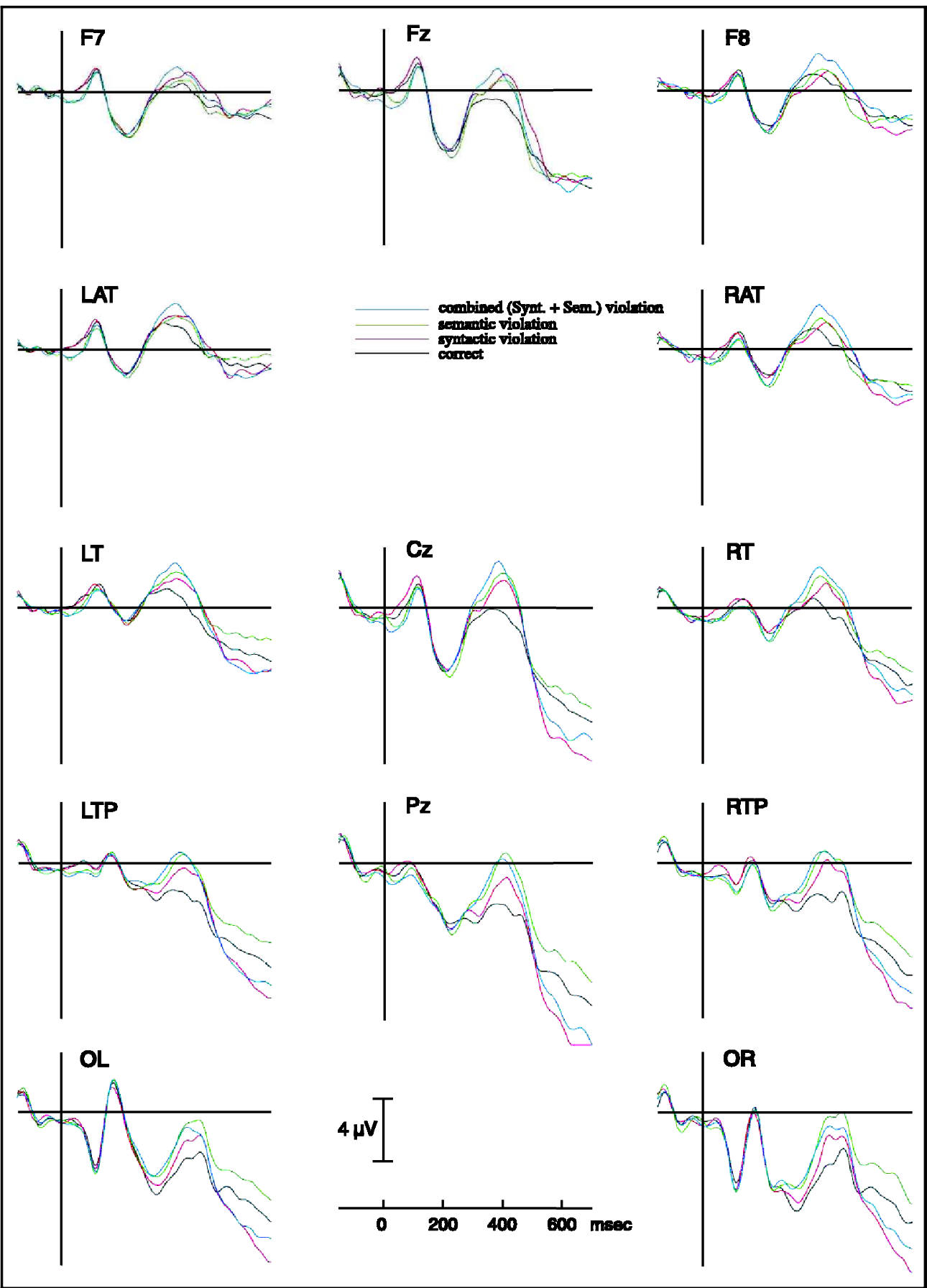

effects of semantics, $F(1,23)=18.22, M S E=25.5, p=$ .0003 , and grammaticality, $F(1,23)=8.06, M S E=19.4$, $p=.009$. These main effects were qualified by a significant three-way Position $\times$ Semantics $\times$ Grammaticality interaction, $F(1,23)=5.07, M S E=11.6, p=.034$. For the sentence-internal position, next to significant main effects of semantics, $F(1,23)=9.67, M S E=18.5, p=$ .0049 , and grammaticality, $F(1,23)=4.78, M S E=12.4$, $p=.039$, there was a marginally significant Semantics $\times$ Grammaticality interaction, $F(1,23)=3.60, M S E=9.1$, $p=.070$. In sentence-final position, only significant main effects of semantics, $F(1,23)=16.49, M S E=17.7, p=$
.0005 , and grammaticality, $F(1,23)=5.64, M S E=17.7$, $p=.026$, were obtained. No significant Semantics $\times$ Grammaticality interaction was observed, $F(1,23)=1.38$, $M S E=19.9, p=.25$. For sentence-internal positions, it thus seems that semantic and syntactic processing factors interact at the level of the N400 amplitude. The omnibus ANOVA was followed by separate analyses per violation type.

For the semantic violation (Sem -), a significant N400 effect was observed, $F(1,23)=9.94, M S E=22.4$, $p=.005$. In addition, the analysis resulted in a significant Semantic Violation $\times$ Position interaction, $F(1,23)=4.57$, 
$M S E=11.6, p=.043$. The $\mathrm{N} 400$ effect was clearly larger in sentence-final than in sentence-internal position. The N400 effect showed a more posterior distribution in the sentence-final condition compared to the sentenceinternal condition. This topographic difference resulted in a significant three-way Position $\times$ Violation $\times$ Electrode interaction, $F(1,23)=6.63, M S E=0.9, p<.05$. For the sentence-internal position, the N400-effect had a slightly more anterior distribution than usual. Although over the midline sites, the N400 effect was maximal over $\mathrm{Pz}$, it became only significant in an analysis on the medial and left anterior-temporal electrode sites Fz, F7, LAT, LT, $F(1,23)=5.00, M S E=10.2, p=.035$. For the sentence-final position, the effect was highly significant, $F(1,23)=11.67, M S E=21.1, p=.002$.

For the syntactic violation (Synt -), the ANOVA supported the impression from Figures 2, 3, 4, and 5. For the 300-500 msec latency range, the syntactic violation resulted in a significant main effect, $F(1,23)=4.77, M S E=$ $15.2, p=.039$. However, this effect was qualified by a marginally significant Violation $\times$ Position interaction, $F(1,23)=3.33, M S E=12.9, p=.081$. Separate analyses for the sentence-internal and sentence-final syntactic violations resulted in a significant effect for the sentence-final position, $F(1,23)=7.77, M S E=14.6$, $p=.011$, but not for the sentence-internal position, $F<1$. In contrast to the semantic violation, an analysis on the medial and left antero-temporal electrode sites for the syntactic violation in sentence-internal position failed to reach significance, $F(1,23)=1.38, M S E=12.8$, $p=.25$.

The combined violation (Synt - , Sem - ) resulted in a significant $\mathrm{N} 400$ effect, $F(1,23)=29.12, M S E=19.8$, $p<.0000$, but the Violation $\times$ Position interaction was not significant, $F<1$. To test for the "syntactic boost" of the semantic N400 effect, in a planned comparison, the N400 effect in the semantic violation condition was directly tested against the N400 effect in the combined violation condition. This analysis resulted in a marginally significant effect, $F(1,23)=$ 4.06, $M S E=20.6, p=.056$. Most critically (see Discussion), for the sentence-internal position, the syntactic boost was highly significant, $F(1,23)=11.27$, $M S E=8.0, p=.003$. No such boost was observed in sentence-final position, $F<1$.

\section{P600/SPS}

As can be seen in the averaged waveforms (Figures 2-5), the N400 amplitude modulations are followed by increased positive shifts for the syntactic violation and for the combined violation. In this case, the analysis of the P600/SPS is complicated by the preceding differences in N400 amplitudes. One way to compensate for this baseline problem is to compute peak-to-peak amplitudes for the N400-P600/SPS (cf. Coles, Gratton, Kramer, \& Miller, 1986). However, determining the peak values for long latency components in single subjects' averaged waveforms is error prone, given the absence of a sharply defined peak. Therefore, the waveforms were renormalized with respect to the N400 latency window. Mean amplitudes were computed relative to the mean amplitude in the latency range of 300-500 msec after onset of the critical noun in the sentence-internal or the sentence-final position.

The omnibus ANOVA on the renormalized amplitude values in the $500-700$ msec latency range resulted in a highly significant effect of grammaticality, $F(1,23)=$ 57.10, $M S E=27.9, p=.0000$. The effect of semantics failed to reach significance, $F(1,23)=2.54, M S E=9.2$, $p=.12$. Neither the Semantics $\times$ Grammaticality interaction, $F<1$, nor the three-way Position $\times$ Semantics $\times$ Grammaticality interaction, $F<1$, were significant. Thus, the amplitude of the P600/SPS seems affected only by the syntactic violation. Again, the omnibus ANOVA was followed by separate analyses for each of the violations.

For the semantic violation (Sem -), the analysis on the renormalized data in the P600/SPS latency range (500$700 \mathrm{msec})$ showed no P600/SPS effect, $F(1,23)=2.49$, $M S E=8.3, p=.13$. The absence of a P600/SPS was found for both sentence-internal and sentence-final semantic anomalies, as indicated by the absence of a Position $x$ Violation interaction, $F(1,23)=1.09, M S E=5.9, p=.31$. As expected, a purely semantic violation does not result in a $\mathrm{P} 600 / \mathrm{SPS}$ effect.

For the syntactic violation (Synt -) the analysis resulted in a highly significant main effect of Violation, $F(1,23)=51.77, M S E=16.6, p<.000$. A marginally significant Position $\times$ Violation interaction, $F(1,23)=$ $3.55, M S E=4.6, p=.07$, was due to a smaller syntactic violation effect in the sentence-internal $(1.4 \mu \mathrm{V})$ than in the sentence-final position $(1.9 \mu \mathrm{V})$, but both effects were highly significant.

Just as for the syntactic violation, a highly significant P600/SPS effect was observed for the combined violation $[$ Synt - , Sem $-: F(1,23)=45.62$, MSE $=22.0, p<.000]$. Again, the effect was slightly smaller for sentenceinternal violations $(1.4 \mu \mathrm{V})$ than for sentence-final violations $(2.2 \mu \mathrm{V})$, resulting in a marginally significant Position $\times$ Violation interaction, $F(1,23)=3.48, M S E=12.3$, $p=.07$. To test for the "semantic boost" of the syntactic P600/SPS effect, in a planned comparison, the P600/SPS effect in the purely syntactic violation condition was directly tested against the P600/SPS effect in the combined violation condition. This analysis substantiated the absence of a semantic boost, $F<1$, for both sentence positions (Position $\times$ Violation interaction, $F<1$ ).

\section{Sentence-Final N400 Effects}

As mentioned in the Introduction, often, local violations or processing problems somewhere in the sentence have a downstream effect on the N400 amplitude, especially to the word in sentence-final position. To 
test for this sentence wrap-up effect, we compared the ERPs elicited by the sentence-final words in sentences with a sentence-internal violation. Figure 6 shows the sentence-final N400 effects for electrode Cz. As can be seen, all three violation types in sentence-internal position resulted in an enlarged and long-lasting negativity to words in sentence-final position. These effects were largest over posterior sites, without clear hemispheric asymmetries.

Effects were computed based on the mean amplitudes in the 300-500 msec latency range relative to a $150 \mathrm{msec}$ baseline preceding the sentence-final word. Averaged over all 13 electrode sites, the N400 effects were present for all three violation types, being largest for the combined violation $(2.0 \mu \mathrm{V})$, slightly smaller for the syntactic violation $(1.6 \mu \mathrm{V})$, and smallest for the semantic violation $(1.1 \mu \mathrm{V})$. The effects were tested in planned comparisons between each violation type and the baseline condition. For the semantic condition, a significant main effect of Violation was obtained, $F(1,23)=8.65$, $M S E=22.6, p=.007$, as well as a significant Violation $\times$ Electrode interaction, $F(1,23)=4.72, M S E=1.2, p<.05$. The interaction was due to the posterior distribution of the effect. For the syntactic violation, the analysis also resulted in a significant main effect of Violation, $F(1,23)=15.43, M S E=26.3, p=.0007$, and a significant Violation $\times$ Electrode interaction, $F(1,23)=10.70$, $M S E=1.4, p<.01$. Finally, the combined violation analysis had a similar outcome, with a highly significant violation effect, $F(1,23)=43.16, M S E=13.8, p=.000$, as well as a significant Violation $\times$ Electrode interaction, $F(1,23)=11.7, M S E=1.3, p<.001$. As for the semantic violation, for the latter two violations, the interactions were the result of the posterior distribution of the effects. These results provide very clear-cut evidence for sentence-final effects of processing problems at earlier positions in the sentence.

\section{Reaction Time Control Study}

At least for the sentence-internal violations, on the basis of the ERP effects, and more in particular on the basis of the latencies of the N400 effect and the P600/SPS effect, one cannot exclude that subjects are slower in detecting syntactic than semantic violations. To test for this possibility, a control study was run, in which subjects were asked to provide speeded responses to the violations. The materials, experimental lists, and presentation parameters were exactly the same as in Experiment 1. Subjects were instructed to read the sentences carefully and to react immediately upon detecting an anomaly. Subjects gave a pushbutton response with the index finger of their dominant hand. Twenty-four paid volunteers (18 women) between 20 and 29 years of age (average: 23.4 years) participated in this control experiment.

\section{Results}

Figure 7 summarizes the results for the three violation types in sentence-internal and sentence-final positions.

For both sentence positions, detection latencies were longer for the semantic violations than for the syntactic and the combined violations. The violation detection
Figure 6. Sentence-final ERP waveforms at $\mathrm{Cz}$ for the sentence-internal conditions. The final word of the sentence is presented at Time 0 .

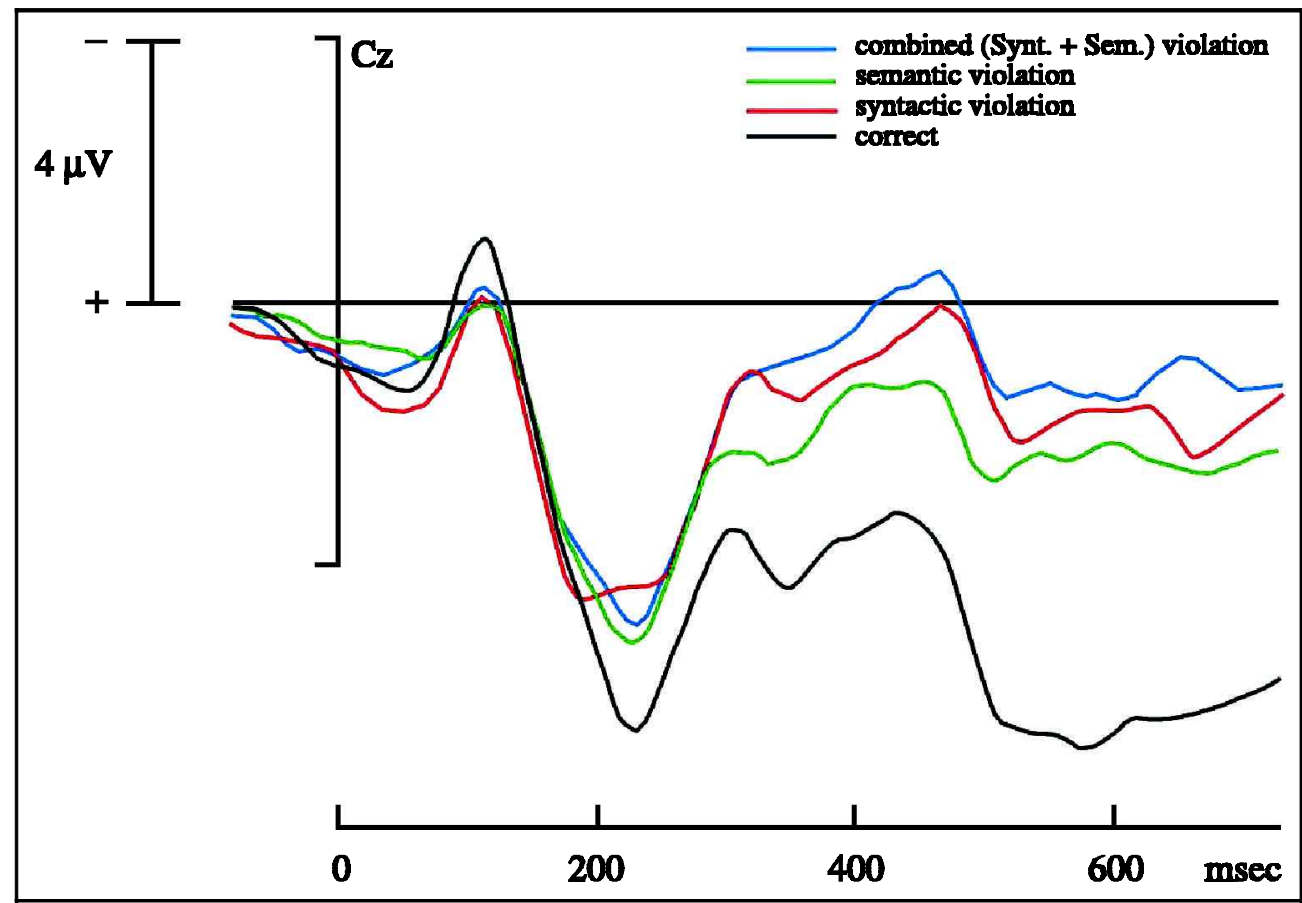




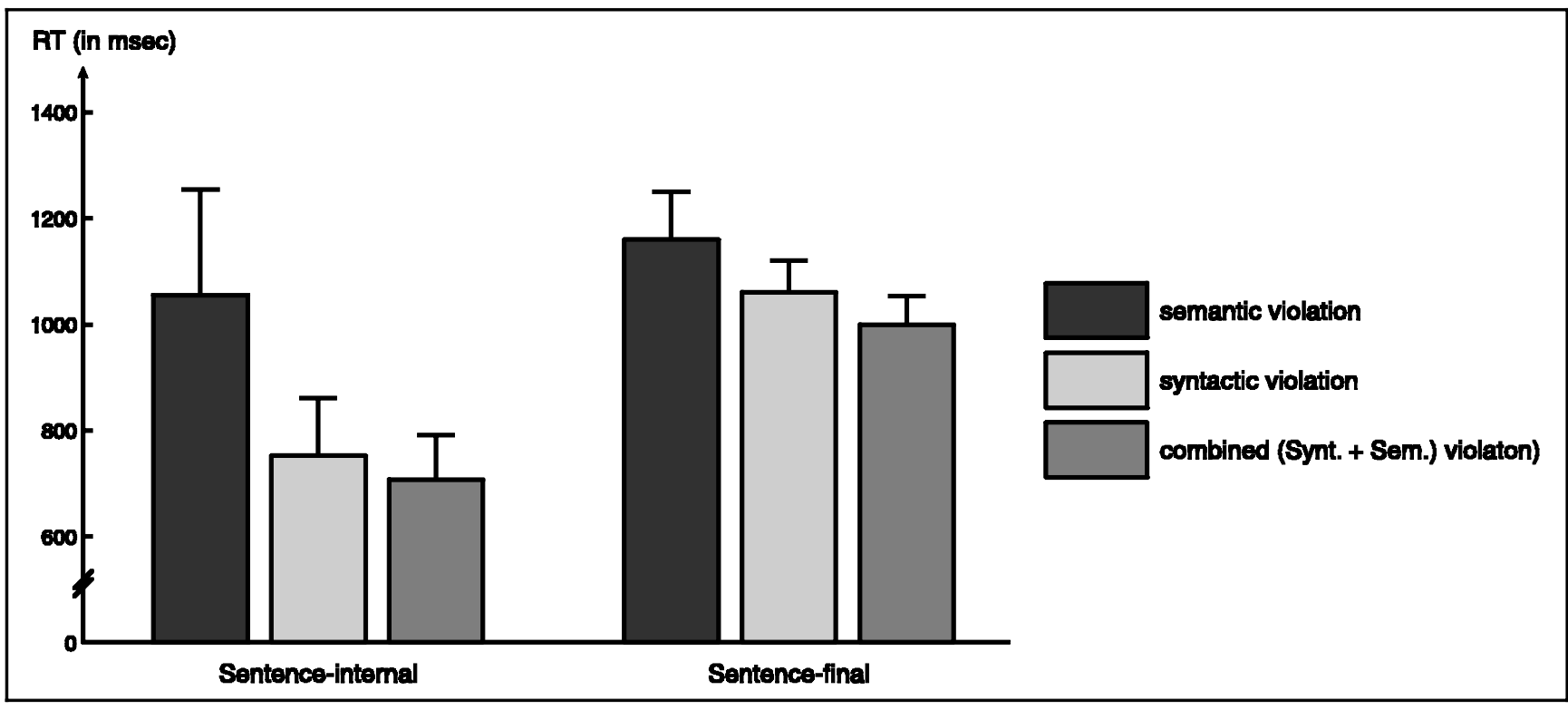

Figure 7. The reaction time results of an on-line (speeded) anomaly detection task version of the experiment. Bars represent mean reaction times and standard deviations for the three violation types in sentence-internal and sentence-final position.

latencies were tested in separate repeated-measures ANOVAs for the sentence-internal and sentence-final violation position, with Violation Type (semantic, syntactic, combined) as the within-subject factor. These analyses resulted in a highly significant effect of Violation Type for both sentence-internal, $F(1,23)=37.0, p<.001$, and sentence-final violations, $F(1,23)=14.6, p<.001$. Overall, the detection latencies for the semantic violation were 200 msec longer than for the syntactic violation, and $254 \mathrm{msec}$ longer than for the combined violation.

These results clearly indicate that the latencies of the relevant ERP effects cannot be predicted by the time it takes to detect the anomaly.

\section{DISCUSSION}

The results of this study can be summarized as follows. In the absence of an interaction between semantic and syntactic analyses during on-line sentence comprehension, the effects of the syntactic and the semantic violations should have been additive. This follows from Helmholtz superposition rule, which says that contributions from nonoverlapping neural generators (i.e., the N400 and the P600/SPS) show additive effects in the scalp-recorded potentials. Because nonadditivity was obtained, the conclusion must be that the processes that feed into these two generator ensembles are interacting at some level.

The results for the syntactic violation were very clear-cut. A violation of the gender or number agreement between the article and the noun in Dutch NPs resulted in a classical P600/SPS (cf. Hagoort et al., 1993; Osterhout \& Holcomb, 1992; Osterhout, McLaughlin, \& Bersick, 1997). This effect was independent of the position of the agreement violation within the sentence. Although, intuitively, the semantic interpretation of the sentences was not particularly affected by the gender/number mismatch between the definite article and the noun, both the acceptability judgements and the brain responses showed a significant sensitivity of the language processing system to violations of gender/ number agreement.

In addition to the P600/SPS, for the syntactic violations an increased negativity was observed in a latency range preceding the P600/SPS. However, this negativity only arose to violations in sentence-final position. Over lateral sites the negativity had the classical distribution of the N400, increasing in amplitude from frontal to posterior sites, and slightly larger over right than left posterior sites. Over the three midline sites $(\mathrm{Fz}, \mathrm{Cz}, \mathrm{Pz})$, the effect was largest over $\mathrm{Cz}$, whereas, classically, the visual N400 is largest over Pz. However, inspection of the waveforms suggests that the $\mathrm{N} 400$ amplitude at the Pz site is reduced due to the overlap of the following P600/SPS, which has a posterior maximum. Thus, although it cannot be completely excluded that the observed negativity is similar to syntax-related negativities with a fronto-central distribution that have been reported in relation to morphosyntactic incongruities (Münte, Matzke, \& Johannes, 1997), it is much more likely that the negativity that we obtained is a classical N400 effect.

The semantic violation resulted in a significant N400 effect. In sentence-final position, the N400 effect was larger than in sentence-internal position. This could be due to the fact that, usually, the strength of the semantic constraints increases towards the end of the sentence. Violation of these constraints, therefore, has a stronger 
effect towards the end of sentence compared to earlier word positions. For the sentence-internal semantic violations, the topography of the effect showed the usual posterior distribution over the midline sites, but over left lateral sites, it had a more anterior distribution than is usually seen.

Crucial for the purpose of this study are the effects of the combined violation in relation to the effects of the single syntactic and semantic violations. A detailed analysis of the obtained N400 and P600/SPS effects showed a syntactic boost for the semantic N400 effect, but no semantic boost of the syntactic P600/SPS effect. This conclusion is based on the finding that the combined violation resulted in a larger increase in the N400 amplitude than a purely semantic violation, but in contrast, no difference in P600/SPS was obtained between the purely syntactic violation and the combined violation.

This pattern of results suggests an asymmetry between semantic and syntactic analysis: Syntactic analysis is unaffected by semantic integration problems. Intuitively, this implies that assigning structure to a Jabberwocky sentence is as easy as assigning structure to a meaningful sentence. Semantic integration is, however, harder in the presence of a syntactic processing problem. More will be discussed on this issue below.

Finally, the syntactic effect is modulated by sentence position. Whereas the syntactic violations in sentenceinternal positions elicited no N400 effect, but only a P600/ SPS, in sentence-final positions, a concomitant N400 effect was observed as well. This N400 effect in sentence-final positions is often seen as result of a processing problem somewhere in the sentence (cf. Hagoort et al., 1993; Osterhout \& Holcomb, 1992, 1993; Osterhout \& Nicol, 1999). Similar findings have been reported in the reading time literature. It is a well-established finding in studies that measure reading times that apart from local effects, sentence-final words are often strong attractors of global processing factors related to sentence wrap-up, decision, and response requirements (e.g., Schriefers, Friederici, \& Kühn, 1995; Mitchell \& Green, 1978). This finding has been replicated with ERPs. For example, in sentences that subjects judge as unacceptable, final words elicit an enhanced N400-like effect, regardless of whether the unacceptability is semantic or syntactic in nature (Hagoort et al., 1993; Osterhout and Holcomb, 1992, 1993). This N400-like effect was also observed in this study. The three different types of violations in sentence-internal position all resulted in a sizeable N400-like effect to the sentence-final word. This additional N400-like effect in sentence-final position is presumably related to the consequences of the earlier violations for the overall integration of the sentential information into one coherent message.

The methodological consequence is that a direct comparison between sentence-internal and sentencefinal effects is often not straightforward. Furthermore, sentence-final effects are sometimes harder to interpret than sentence-internal effects. As we have seen, presenting a violation in sentence-final position might result in the summation of the local violation effect and its consequences for sentence wrap-up. If one is interested in local effects of language processing that impact other components than the N400, it is not always possible to disentangle these from the effects of global processing costs that show up most clearly in sentence-final position.

Nevertheless, the sentence-final data present an interesting puzzle. This is that for the purely syntactic violation in sentence-final position the N400 effect precedes the P600/SPS in time, which raises the following issue: What does the latency of the P600/SPS imply about the time course of syntactic analysis versus semantic integration processes? The fact that the syntactic violation had its impact already on the $\mathrm{N} 400$ proves that the relevant syntactic information was available before it manifested itself in the P600/SPS. Earlier syntax-related ERP effects in the literature (e.g., Friederici et al., 1996) support this claim. The relative onset of N400 effects and the P600/SPS, therefore, cannot be taken as a direct estimate of the relative time courses of parsing operations and semantic integration processes. Two potential explanations for the onset differences between the N400 effect and the P600/SPS are offered.

One explanation relates to the general nature of language-relevant ERPs. Currently, there is no single language-relevant ERP for which the claim can be made that it is language specific. That is, we do not know whether the different language processing events that we are interested in are directly or only indirectly reflected in the ERP effects. This complication has its parallel in PET and fMRI where it is often unknown whether an area of an increased hemodynamic response is the source of the cognitive operation or the site where it has its effect. With respect to ERPs, with their millisecond time-course resolution, we face the problem that if the scalp-recorded potential is only indirectly related to the cognitive operation under investigation, the time course of the ERP can be displaced in time relative to the time course of the cognitive operation by an unknown amount. This implies that the latency of an ERP effect reflects the upper bound on the estimation of the time course of a cognitive operation (Rugg \& Coles, 1995). ${ }^{1}$ The onset of the cognitive operation might have preceded the moment where it started to manifest itself in its ERP index. Moreover, this delay is not necessarily identical for the different language-relevant ERP effects. Undoubtedly, this complicates deriving straightforward conclusions from the relative moments in time of qualitatively distinct ERP effects. It could, in part, explain the delay of the P600/SPS relative to the onset of the N400 effect.

However, for all we know about the speed of information transmission in the brain, most likely, the actual onset difference between N400 effect and P600/SPS can 
only be partly explained by differences in the delay between a cognitive process and its ERP manifestation. Functional differences related to the cognitive architecture of language comprehension might also be at stake. One such difference is that semantic integration is a very immediate process (Marslen-Wilson, 1989). The processing costs involved in integrating word meaning into the ongoing sentence interpretation can vary, resulting in modulations of the N400 amplitude. The P600/SPS, however, might be related to the outcome of parsing operations rather than directly reflecting these operations themselves. That is, if a parsing operation fails because unification of the syntactic building blocks cannot take place on the basis of the available feature specifications (cf. Vosse \& Kempen, 2000), a P600/SPS is elicited. If this functional interpretation is correct, it implies that the P600/SPS is not directly related to the unification process itself, but to its failure, which follows this process in the case of feature mismatch. Under this account, the processing consequences for a more complicated unification process might already be felt in the semantic integration operations before the unification process comes to a halt.

Paradoxically, the behavioral data from the on-line anomaly detection task showed that it took subjects much longer to evaluate the semantic acceptability than the syntactic acceptability of the sentences. However, indirectly, these data support the proposed processing distinction underlying the N400 and the P600/SPS effects. Most likely, the anomaly detection for the syntactic conditions is based on the fact that for the gender/ number features, unification takes place if the gender and number features of the article and the noun match, and it fails if these features do not match. This lends itself naturally for a mapping onto the two response categories: correct versus anomalous. Semantic integration is a much more graded process. Some word meanings are more difficult to integrate into the context than other word meanings. However, there does not seem to be a clear boundary between what can be integrated and what cannot be integrated in the semantics of the context, between what is harder to integrate and what is impossible to integrate. The semantic distinctions are less categorical than the syntactic distinctions. Thus, the anomaly detection for the semantic violations might be based on a measure of processing complexity, where more processing "evidence" has to accumulate before it maps onto the category "anomalous."

The results of this study replicated the finding of other studies on the combination of semantic and syntactic anomalies, in that single semantic violations resulted in N400 effects, and single syntactic violations in P600/SPS effects (Friederici et al., 1999; Osterhout \& Nicol, 1999; Ainsworth-Darnell et al., 1998; Gunter et al., 1997). However, this study differs from other studies in the results for the combined violation. One reason for this difference might be related to the position of the violation in the sentence, which was sentence-final in two studies (Friederici et al., 1999; Gunter et al., 1997). In contrast to this study, Osterhout and Nicol (1999) found that the combined effect was an approximate (but not perfect) summation of the single violation effects. In their case, the ERPs in the different conditions were to nonidentical lexical items, which could have contributed to the differences between their results and the findings of this study. In addition, the type of syntactic violation (Osterhout and Nicol used verb tense violations) and language (English vs. Dutch) might also have contributed in unknown ways to the differences in results. Further testing will be necessary to determine whether the findings reported here can be generalized across languages and syntactic violation types.

In summary, given the summation of local and global processing effects in sentence-final ERPs, the effects in sentence-internal positions are more straightforward with respect to the interplay between syntactic and semantic processes than the results in sentencefinal position. Taking this positional difference into consideration, the main conclusions of this study are as follows: The consequences of a semantic violation on the N400 amplitude are boosted by an additional syntactic violation. In contrast, the consequences of a syntactic violation on the amplitude of the P600/SPS are unaffected by an additional semantic violation. This suggests an asymmetry between semantic and syntactic processing. The assignment of syntactic structure is unaffected by semantic information. In contrast, semantic integration is influenced by syntactic information. Similar findings have been reported in a series of naming experiments by O'Seaghdha (1997).

However, one important qualification has to be made in relation to this interpretation of the results. The finding that syntactic processing seems unaffected by semantic context should be restricted to those cases in which the incremental build-up of syntactic structure on the basis of the incoming word input is deterministic. This differs from the case of syntactic ambiguity, where at specific moments in the structural assignment process, more than one syntactic structure can be assigned. For instance, in the sentence fragment "John kissed his sister and his uncle ...," "his sister and his uncle" can be interpreted as a NP (as in "John kissed [his sister and his uncle] before he left the house"), or, alternatively, as belonging to two different clauses (as in "[John kissed his sister] and [his uncle started the engine of the car]"'). There is clear evidence from both behavioral data and from ERP recordings that lexical context (Hagoort et al., 1999; Osterhout et al., 1994; Trueswell et al., 1993) and discourse context (van Berkum et al., 1999; Ni, Crain, \& Shankweiler, 1996; Altmann \& Steedman, 1988) immediately influence the assignment of structure when there are different structural options. Thus, syntactic constraints conspire with semantic constraints if the latter are necessary for determining structure, but semantics is 
ignored by syntax if its contribution is not needed. Syntax is selfish, whereas semantics is altruistic.

\section{METHODS}

\section{Materials}

For the purposes of this study, the relevant materials consisted of 320 items. These items consisted of four versions, one for each type of violation. Each of these sentence quartets contained one sentence with a violation of the gender and/or number agreement between the definite article and the noun (Synt -), one sentence with a semantic violation due to a semantically unacceptable combination of the adjective and the following noun (Sem -), a sentence with the combination of these two violations (Synt -, Sem -), and, finally, the semantically and syntactically correct sentence (for an example of the materials, see Table 1). In the semantically correct and the semantically anomalous conditions, different adjectives preceded the nouns in the CW position. These adjectives were matched in length and frequency. Half of the critical sentences contained the violation in the first NP of the sentence, the other half in the sentence-final NP. Critically, for both sentenceinternal and sentence-final violations, the violation of the gender/number agreement and the violation of the semantic constraint became clear at the same noun. Thus, lexical differences could not interfere with the violation effects.

The materials were constructed so that $50 \%$ of the sentences contained a syntactic violation, and 50\% of the sentences contained a semantic violation. For half of the sentences, the critical noun was presented in its plural form. To make sure that violations of gender/ number agreement could occur with equal probability after a common gender and a neuter gender article, 160 filler sentences were added. In this way, violations of gender/number agreement could not be predicted on the basis of probability or sentence context. The materials were distributed among four versions of the experiment such that no subject saw more than one version of a sentence quartet, but across subjects, the critical items were distributed equally over all conditions.

In addition to experimental items and filler items, the materials included 20 practice items and 15 startup items. Sentences had a mean length of 7.7 words $(S D=1.2$ words $)$. Words were never longer than 12 letters, with nouns in the $\mathrm{CW}$ position having a maximal length of 10 letters. All sentences were simple active or passive sentences. The materials are available from the author upon request.

\section{Participants}

Twenty-four young subjects from the subject pool of the Max Planck Institute (20 women) participated in this study. Subjects ranged in age from 21 to 34 years, with a mean age of 24.6 years. All subjects had normal or corrected-to-normal vision and were right-handed, and they had no neurological history. Subjects were paid for their participation.

\section{Procedure}

Subjects were asked to read the sentences carefully for comprehension, and to indicate for each sentence whether or not it was acceptable. Sentences were presented word by word in the center of a highresolution computer screen. Each word was presented for $300 \mathrm{msec}$, followed by a blank screen for another $300 \mathrm{msec}$, after which the next word of the sentence appeared. The final word of the sentence was presented together with a period sign. After a variable delay (minimally $1 \mathrm{sec}$ ) from sentence offset, a row of asterisks appeared on the screen, signaling to the subjects that they had to push one of two response buttons indicating whether the sentence was acceptable or not. Subjects were advised to blink their eyes during the presence of the asterisks in order to reduce the probability of eye movements in the critical epochs. The row of asterisks remained on the screen for a period of $2 \mathrm{sec}$, followed by a blank screen for a period of $1150 \mathrm{msec}$ preceding the next sentence.

The test session started with a practice block of 20 practice items to familiarize the subjects with the procedure. The experimental items were presented in five blocks of 15 min each, with a short break between each block. The first three items of each block were start-up items. The whole test session lasted approximately $1 \mathrm{hr}$ and $45 \mathrm{~min}$.

\section{EEG Recording and Analysis}

ERPs were recorded from 13 electrode sites across the scalp, using an Electrocap with 13 tin electrodes, each referred to the left mastoid. ERPs were recorded from three midline positions $(\mathrm{Fz}, \mathrm{Cz}, \mathrm{Pz})$ and two frontal sites (F7, F8) placed according to the International 10-20 system (Jasper, 1958). In addition, ERPs were recorded from left and right anterior temporal sites (LAT, RAT), left and right temporal (LT, RT), left and right temporoparietal (LTP, RTP), and left and right occipital sites (OL, OR). LAT and RAT were placed midway between T3-F7 and T4-F8, respectively. LT and RT were placed 33\% of the interaural distance lateral to Cz. LTP and RTP were placed $30 \%$ of the interaural distance lateral to $\mathrm{Cz}$ and $13 \%$ of the inion-nasion distance posterior to Cz. OL and OR were placed midway between $\mathrm{O} 1-\mathrm{T} 5$ and $\mathrm{O} 2-$ T6, respectively. Vertical eye movements and blinks were monitored via a supra- to suborbital bipolar montage. A right to left canthal bipolar montage was used to monitor for horizontal eye movements. Activity over the right mastoid was recorded on an additional channel to determine if there were differential contributions of the 
experimental variables to the two presumably neutral mastoid sites. No such differential effects were observed.

The EEG and EOG recordings were amplified with Nihon Kohden AB-601G bioelectric amplifiers, using a $\mathrm{Hi}-\mathrm{Cut}$ of $30 \mathrm{~Hz}$ and a time constant of $8 \mathrm{sec}$. Impedances were kept below $5 \mathrm{k} \Omega$. The EEG and EOG were digitized on-line with a sampling frequency of $200 \mathrm{~Hz}$. Sampling started $150 \mathrm{msec}$ before the onset of the sentence and continued until the asterisks appeared on the screen. The experimental trials were stored along with condition codes for off-line averaging and data analysis.

Prior to off-line averaging, all single trial waveforms were screened for electrode drifting, amplifier blocking, muscle artifacts, eye movements, and blinks. Trials containing artifacts were rejected. The overall rejection rate was $16.2 \%$, equally distributed over conditions.

\section{Acknowledgments}

The research reported was supported by a grant from the Netherlands Organization for Scientific Research (NWO), grant number 400-56-384. I thank Colin Brown and Michael Coles for their comments on earlier versions of this manuscript.

Reprint requests should be sent to Peter Hagoort, F.C. Donders Centre for Cognitive Neuroimaging, PO Box 9101, NL-6500 HB Nijmegen, The Netherlands, or via e-mail: peter.hagoort@fcdonders.kun.nl.

\section{Note}

1. What we do not know for language-relevant ERP effects, we do know for the lexical decision task, naming, and other speeded response measures. All these measures are indirect, because they require at least transmission of information from brain areas relevant for a cognitive operation to the motor cortex in order to result in the actual execution of the speeded response. This obvious fact is often ignored in on-line RT studies of language processing.

\section{REFERENCES}

Ainsworth-Darnell, K., Shulman, H., \& Boland, J. (1998). Dissociating brain responses to syntactic and semantic anomalies: Evidence from event-related potentials. Journal of Memory and Language, 38, 112-130.

Altmann, G. T. M., \& Steedman, M. (1988). Interaction with context during human sentence processing. Cognition, 30, $191-238$

Boland, J. E., \& Cutler, A. (1996). Interaction with autonomy: Multiple output models and the inadequacy of the great divide. Cognition, 58, 309-320.

Brown, C., \& Hagoort, P. (1993). The processing nature of the N400: Evidence from masked priming. Journal of Cognitive Neuroscience, 5, 34-44.

Brown, C., \& Hagoort, P. (1999). On the electrophysiology of language comprehension: Implications for the human language system. In M. Crocker, M. Pickering, \& C. Clifton (Eds.), Architectures and mechanisms for language processing (pp.213-237). Cambridge, UK: Cambridge University Press.

Chwilla, D. J., Brown, C. M., \& Hagoort, P. (1995). The N400 as a function of the level of processing. Psychophysiology, 32, $274-285$.

Coles, M. G. H., Gratton, G., Kramer, A., \& Miller, G. A. (1986) Principles of signal acquisition and analysis. In M. G. H. Coles, E. Donchin \& S. W. Porges (Eds.), Psychophysiology: Systems, processes, and applications (pp. 183-221). New York: Guilford Press.

Fodor, J. D. (1993). Reply to Block and Boghossian. Mind and Language, 8, 41-48.

Frazier, L. (1987). Sentence processing: A tutorial review. In M. Coltheart (Ed.), Attention and performance XII (pp. 559-585). London: Erlbaum.

Friederici, A. D., Hahne, A., \& Mecklinger, A. (1996). Temporal structure of syntactic parsing: Early and late event-related brain potential effects. Journal of Experimental Psychology: Learning, Memory, and Cognition, 22, 1219-1248.

Friederici, A. D., Steinhauer, K, \& Frisch, S. (1999). Lexical integration: Sequential effects of syntactic and semantic information. Memory and Cognition, 27, 438-453.

Gunter, T. C., Stowe, L. A., \& Mulder, G. M. (1997). When syntax meets semantics. Psychophysiology, 34, 660-676.

Hagoort, P., \& Brown, C. M. (1999). Gender electrified: ERP evidence on the syntactic nature of gender processing. Journal of Psycholinguistic Research, 28, $715-728$.

Hagoort, P., Brown, C. M., \& Groothusen, J. (1993). The syntactic positive shift (SPS) as an ERP-measure of syntactic processing. Language and Cognitive Processes, 8, $439-483$

Hagoort, P., Brown, C. M., \& Osterhout, L. (1999). The neurocognition of syntactic processing. In C. M. Brown \& P. Hagoort (Eds.), The neurocognition of language (pp. 273-316). Oxford, UK: Oxford University Press.

Hagoort, P., Wassenaar, M., \& Brown, C. M. (2003). Syntaxrelated ERP effects in Dutch. Cognitive Brain Research, 16, $38-50$.

Jackendoff, R. (1999). The representational structures of the language faculty and their interactions. In C. M. Brown \& P. Hagoort (Eds.), The neurocognition of language (pp. 37-79). Oxford, UK: Oxford University Press.

Jackendoff, R. (2002). Foundations of language: Brain, meaning, grammar, evolution. Oxford, UK: Oxford University Press.

Jasper, H. H. (1958). Report to the committee on methods and clinical examination in electroencephalography. Appendix: The ten-twenty system of the International Federation. Electroencephalography and Clinical Neurophysiology, 10, $371-375$.

Kutas, M., \& Hillyard, S. A. (1980). Reading senseless sentences: Brain potentials reflect semantic anomaly. Science, 207, 203-205.

Levelt, W. J. M. (1999). Producing spoken language: A blueprint of the speaker. In C. M. Brown \& P. Hagoort (Eds.), The neurocognition of language (pp. 83-122). Oxford, UK: Oxford University Press.

Marslen-Wilson, W. (1989). Access and integration: Projecting sound onto meaning. In W. Marslen-Wilson (Ed.), Lexical representation and process (pp. 3-24). Cambridge: MIT Press.

Mitchell, D. C., \& Green, D. W. (1978). The effects of context and content on immediate processing in reading. Quarterly Journal of Experimental Psychology, 30, 609-636.

Münte, T. F., \& Heinze, H. J. (1994). ERP negativities during syntactic processing of written words. In H. J. Heinze, T. F. Münte, \& G. R. Mangun (Eds.), Cognitive electrophysiology. Boston: Birkhauser. 
Münte, T. F., Heinze, H. J., \& Mangun, G. R. (1993). Dissociation of brain activity related to syntactic and semantic aspects of language. Journal of Cognitive Neuroscience, 5, 335-344.

Münte, T. F., Matzke, M., \& Johannes, S. (1997). Brain activity associated with syntactic incongruities in words and pseudo-words. Journal of Cognitive Neuroscience, 9, $300-311$.

Ni, W., Crain, S., \& Shankweiler, D. (1996). Sidestepping garden paths: Assessing the contributions of syntax, semantics and plausibility in resolving ambiguities. Language and Cognitive Processes, 11, 283-334.

O'Seaghdha, P. G. O. (1997). Conjoint and dissociable effects of syntactic and semantic context. Journal of Experimental Psychology, 23, 807-828.

Osterhout, L., \& Hagoort, P. (1999). A superficial resemblance doesn't necessarily mean you're part of the family: Counterarguments to Coulson, King, and Kutas (1998) in the P600/SPS debate. Language and Cognitive Processes, 14, $1-14$

Osterhout, L., \& Holcomb, P. J. (1992). Event-related brain potentials elicited by syntactic anomaly. Journal of Memory and Language, 31, 785-806.

Osterhout, L., \& Holcomb, P. J. (1993). Event-related potentials and syntactic anomaly: Evidence of anomaly detection during the perception of continuous speech. Language and Cognitive Processes, 8, 413-438.

Osterhout, L., Holcomb, P. J., \& Swinney, D. A. (1994). Brain potentials elicited by garden-path sentences: Evidence of the application of verb information during parsing. Journal of Experimental Psychology: Learning, Memory, and Cognition, 20, 786-803.

Osterhout, L., McLaughlin, J., Bersick, M. (1997). Event-related brain potentials and human language. Trends in Cognitive Sciences, 1, 203-209.

Osterhout, L., \& Nicol, J. (1999). On the distinctiveness, independence, and time course of the brain responses to syntactic and semantic anomalies. Language and Cognitive Processes, 14, 283-317.

Rugg, M. D., \& Coles, M. G. H. (1995). The ERP and cognitive psychology: Conceptual issues. In M. D. Rugg \& M. G. H. Coles (Eds.), Electrophysiology of mind: Event-related brain potentials and cognition (pp. 27-39). Oxford, UK: Oxford University Press.

Schriefers, H., Friederici, A. D., \& Kühn, K. (1995). The processing of locally ambiguous relative clauses in German. Journal of Memory and Language, 34, 499-520.

Tanenhaus, M. K., \& Trueswell, C. (1995). Sentence comprehension. In J. L. Miller \& P. D. Eimas (Eds.) Speech, language, and communication (pp. 217-262). San Diego, CA: Academic Press.

Trueswell, J. C., Tanenhaus, M. K., \& Garnsey, S. M. (1994). Semantic influences on parsing: Use of thematic role information in syntactic ambiguity resolution. Journal of Memory and Language, 33, 285-318.

Trueswell, J. C., Tanenhaus, M. K., \& Kello, C. (1993). Verbspecific constraints in sentence processing: Separating effects of lexical preference from garden-paths. Journal of Experimental Psychology: Learning, Memory, and Cognition, 19, 528-553.

Tyler, L. K., \& Marslen-Wilson, W. D. (1977). The on-line effects of semantic context on syntactic processing. Journal of Verbal Learning and Verbal Behavior, 16, 683-692.

van Berkum, J. J. A. (1996). The psycholinguistics of grammatical gender. Published doctoral dissertation. Nijmegen, The Netherlands: Nijmegen University Press.

van Berkum, J. J. A., Brown, C. M., \& Hagoort, P. (1999). Early referential context effects in sentence processing: Evidence from event-related brain potentials. Journal of Memory and Language, 41, 147-182.

van Berkum, J. J. A., Hagoort, P., \& Brown, C. M. (1999). Semantic integration in sentences and discourse: Evidence from the N400. Journal of Cognitive Neuroscience, 11, $657-671$.

Vosse, Th., \& Kempen, G. (2000). Syntactic structure assembly in human parsing: A computational model based on competitive inhibition and lexicalist grammar. Cognition, 75, 105-143.

Winer, B. J. (1971). Statistical principles in experimental design (2nd ed.). New York: McGraw-Hill. 
Copyright $\odot 2003$ EBSCO Publishing 
Copyright $\odot 2003$ EBSCO Publishing 